\title{
Development of the Oxygen Converter Gas Recovery Process (OG Process)
}

\section{and Its Economy*}

\author{
By Masao Yukawa** and Keiji Okaniwa***
}

\section{Background of the Development of OG Process}

\section{Collection of Oxygen Converter Generated Gas}

The development of the oxygen converter process is one of the most creditable technological innovations in the history of the iron and steel industry. As seen in Table 1, the process has achieved a phenomenal progress particularly in Japan. It is, therefore, not too much to say that it constitutes a firm backbone for the prosperity of the iron and steel industry in this country.

The most conspicuous advantages of the oxygen converter process, which greatly attracted the Japanese industry on the way toward the expansion of the equipment, are low operation expenses due to high productivity, and low cost of construction as compared with the open hearth process which formerly was the major, prevailing steelmaking method.

It is, however, inevitable in this newly developed process utilizing much pure oxygen that a large volume of high calory waste gas is produced containing particles of iron oxide. And accordingly, to cope with this problem, it became necessary to construct huge waste heat recovery boilers and dust collectors at staggering expenses.

Table 1. Oxygen converters in the world (Unit : 1,000 tons)

\begin{tabular}{|c|c|c|c|c|}
\hline & \multicolumn{2}{|c|}{$\begin{array}{c}\text { Oxygen converters } \\
\text { started operation } \\
\text { by } 1962\end{array}$} & \multicolumn{2}{|c|}{$\begin{array}{l}\text { Oxygen converters } \\
\text { scheduled to start } \\
\text { operation by } 1965\end{array}$} \\
\hline & $\begin{array}{l}\text { Annual } \\
\text { capacity } \\
(\mathrm{t})\end{array}$ & $\begin{array}{l}\text { No. of } \\
\text { oxygen } \\
\text { converters }\end{array}$ & $\begin{array}{l}\text { Annual } \\
\text { capacity } \\
(\mathrm{t})\end{array}$ & $\begin{array}{l}\text { No. of } \\
\text { oxygen } \\
\text { converters }\end{array}$ \\
\hline Austria & 1,790 & 7 & 1,790 & 7 \\
\hline Belgium & 1,900 & 5 & 3,890 & 11 \\
\hline Brazil & 1,980 & 8 & 2,280 & 13 \\
\hline Canada & 1,720 & 7 & 1,720 & 7 \\
\hline France & - & 5 & - & 21 \\
\hline Italy & 550 & 1 & 4,200 & 6 \\
\hline Japan & 10,480 & 24 & 17,970 & 39 \\
\hline The Netherlands & 2,650 & 5 & 2,650 & 5 \\
\hline U.S.S.R. & 2,300 & 7 & 12,350 & 21 \\
\hline England & 3,930 & 11 & 3,930 & 11 \\
\hline U.S.A. & 11,510 & 22 & 12,510 & 24 \\
\hline West Germany & 4,950 & 17 & 13,110 & 32 \\
\hline Others & 3,230 & 17 & 7,640 & 31 \\
\hline
\end{tabular}

(Tekko Kai Ho, No. 641, September 1, 1963)

\section{Problems in Conventional Process}

The conventional process, namely the process of complete combustion of waste gas at the top of the converter, utilization of waste heat in the boiler, and finally the performance of dust collection, has the following problems.

(1) High calories produced during refining are estimated at approx. $245,000 \mathrm{kcal} / \mathrm{t}$ steel, that is, the 130-ton converter generates approximately 32,000,000 kcal/heat.

(2) Large volume of waste gas:

Since the generated gas whose main constituent is carbon monoxide is burned with the air at the top of the converter, the 130-ton converter generates a stupendous amount of waste gas, reaching approximately $342,000 \mathrm{~m}^{3} /$ heat $\left(1,850^{\circ} \mathrm{C}\right)$.

(3) Variation of the amount of generated gas and its calories:

The gas and its calories are generated intermittently and accordingly their amounts vary forming peaks, because the operation of the converter is performed intermittently.

(4) Huge dust collector:

As the dust particles generated are extremely minute and moreover the volume of gas is enormous, a huge dust collector is required.

(5) Necessity of tall structure:

When the waste heat boiler is installed, the 130-ton converter requires a structure for this purpose approximately 50 meter high which will be the highest building in the works.

(6) Low energy recovering efficiency:

Energy recovery is now being performed only at an extremely low rate because of the aforementioned reasons, particularly for the reason that the operation is made intermittently. That is, although the thermal efficiency of boilers for power generation and for general purposes as well is more than 85 per cent, that of the waste heat boiler is 60 per cent.

\section{Necessity of Oxygen Converter Gas Recovery}

Along with the trend toward a larger oxygen converter, it is quite apparent that conventional waste heat boiler is not economical.

If the generated gas is recovered in the unburned state, it is theoretically possible to lower the gas temperature to $1,250^{\circ} \mathrm{C}$, to decrease the amount of gas volume to about one sixth, i.e., to $59,500 \mathrm{~m}^{3} /$ heat, and to hold the sensible heat within one sixth, namely to $5,700,000 \mathrm{kcal} /$ heat. Consequently the recovering equipment can be designed to be very compact.

Meanwhile, recovered gas can be utilized as fuel, as the occasion demands. Also due to the high content of $80 \% \mathrm{CO}$, the gas may be utilized as a raw material for the organic chemical industry. In the light of such conditions, it is natural to consider the realization of these merits of the gas recovery process. However, the development of devices which enable the separa-

\footnotetext{
* Lecture delivered by Mr. Masao Yukawa before the Lecture Meeting of The Iron \& Steel Institute of Japan which was held on September 26, 1963 at Bridgestone Hall in Tokyo.

** Representative Director, Executive Vice-President, Yawata Iron \& Steel Co., Ltd.

*** Executive Director, Yokoyama Engineering Co., Ltd.
} 
tion of $\mathrm{CO}$ rich gas from the atmosphere and ensure the prevention of explosion was not easily solved. Therefore no iron and steel company in the world has succeeded in the practical adoption of this concept.

\section{Development of OG Process}

\section{Start of Joint Research on $O G$ Process}

Since Yawata Iron \& Steel Co. finished the construction of the Kukioka LD plant equipped with conventional waste gas equipments in 1957, this company fully recognized the merits of the unburned gas recovery and started to examine the possible measures of solving this question. Meanwhile, Yokoyama Engineering Co., Ltd., after an examination of the same problem from the standpoint of a boiler manufacturer, also came up with a concrete idea for gas recovery. However, as there were many problems to be solved before hand, both companies agreed to make a joint research for the development of the OG process.

\section{Organization and Assignment of Joint Research}

Besides the knowledge about the engineering of the converter and its operation, it was essential to have various other knowledge about the nature of the gas, heat exchange, dust collection, and so on for this development. Having headquarters in the Technical Department of the Head Office of Yawata Iron \& Steel Co., Ltd., the engineers from both companies formed the OG committee in October, 1959, through which it decided to jointly push forward an organized research with all efforts for this development. The term " OG" stands for "Oxygen Converter Gas Recovery". The title of the Committee, "OG", was later adopted as the designation for this process.

The tasks of the OG Committee were the examination of intermediate results of research and the steering of the planning and performing of the joint research, with the view of adding a theoretical examination particularly to the study of the problems pertaining to perfect prevention of explosions. The Committee arranged to receive special guidance from Kiroku Yamazaki, professor at Tokyo University, and Rempei Goto, professor at Kyoto University, both of whom are authorities in this field.

In addition, since this process naturally requires adoption of high-precision meters, the meters themselves are required to be high and advanced in performance; accordingly, we acquired the participation of the Fuji Electric Mfg. Co., Ltd. in this project a little after the formation of the Committee, which resulted in a vigorous pursuit in this field.

\section{Fundamental Research}

The basic aim of the research and development is to completely recover hot gas principally containing carbon monooxide generated from the oxygen converter, by tightly sealing the outlet of the converter to prevent the hot gas from making contact with the external air, subsequently cooling the gas in the unburned state, and by removing dust from the gas by means of a series of dust collectors. The principal part of the method which was to be adopted for this purpose consisted in the sealing of the outlet of a converter for keeping apart combustible hot $\mathrm{CO}$ gas from the external air by forming around it an inactive gas curtain of nitrogen, which is available from the waste gas of the oxygen generator for the converter plant. However, the realization of this method could be conceivable only after solving many problems, of which some of the most important are as follows:

(1) A method of forming an effective curtain of nitrogen gas around the top of the converter.

(2) A method of preventing air from entering the converter by tightly sealing the opening of the oxygen blowing lance of the converter and the fluxing material feeding hopper.

(3) Accurate control of the converter gas pressure, especially the pressure at the outlet of the converter, grasping the dynamic characteristics of the whole recovery system.

(4) Particularly, as important measures for prevention of gas explosions:

i. Making the relation between gas combustion and gas composition clear, especially deciding the tolerance limits of hydrogen and oxygen

ii. Relation between gas flame propagation velocity, and gas flowing velocity.

iii. Solution of the problem of how to develop a method of quickly discharging or absorbing energy in case a sudden combustion of gas in the gas recovery system takes place.

iv. Designing of a proper gas circuit throughout the gas recovery system to avoid the danger of a gas combustion.

(5) Adoption of an automatic control and perfect sequence.

(6) Development of an oxygen analyzer which is capable of making a quick response to any irregularity in the oxygen gas recovery system.

Needless to say, most of these problems could not be solved without basic, theoretical study and tests. The problems were solved consecutively by performing successful tests, using a pilot plant.

As to the pilot plant, a hermetically-sealed waste gas discharger for the discharging of waste gas in the unburned state was already being used at the 200-kg LD test converter in the Technical Research Institute of Yawata Iron \& Steel Co., Ltd. It was, however, small and unsuitable as a preparatory test plant for 
future designing and building of a large-type converter plant with $O G$ equipment.

An OG test plant having a 2-ton converter was installed in the 3rd Steel Making Plant, Yawata Works for the purpose of performing various experiments. An outline of the plant is shown in Fig. 1. The hot metal discharged from the special small mixer is further led into the tilted converter by opening the nozzle at the bottom of the pan. At the top of the converter was installed the movable hood which had the gas curtain forming mechanism. The hood was provided with a lance sealing device and the fluxing material feeding device. The gas passes the hood, gas cooler and the dust collector, and is led by the blower, through the three-way valve, either to the tank or to the stack. The hood pressure can be controlled automatically



Damper for automatically controlling internal pressure of the converter only by operating the damper.

By using the 2-ton test converter, the following tests, survey and analysis were carried out.

(1) Purge test

(2) Blowing test

(3) Tests on the three way valve and the gas holder

(4) Test on the dust collector

(5) Survey of the characteristics of dust collected

(6) Gas analysis

Given below is a brief description of each of the tests.

\section{(1) Purge Test}

With a view to reducing the amount of oxygen present in each part of the gas recovery plant to below the explosion limit given in Fig. 2 at the time when
Fig. 1.

Schematic diagram of a 2-ton test converter 


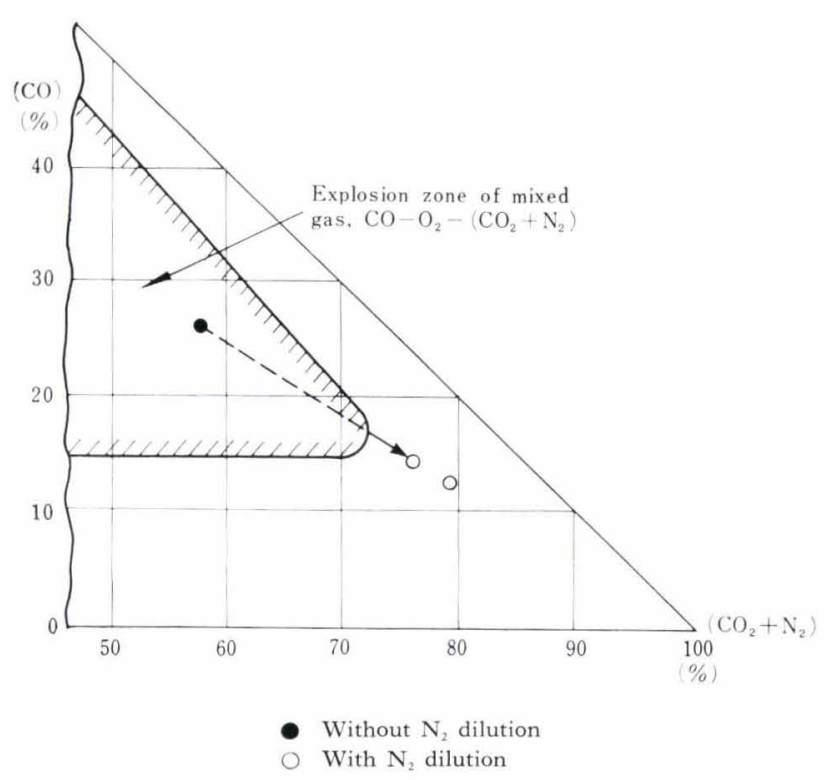

Fig. 2. Effect of $\mathrm{N}_{2}$ dilution in early stage of blowing

the blowing of oxygen into the converter was started, the purging method utilizing nitrogen was adopted. Purging time and amount of nitrogen required at the early and last stage of blowing were obtained; that is, we were able to obtain the standard. A short purging time has no influence upon adequate steelmaking efficiency and only a small amount of nitrogen gas is required to perform the work at a very low expense.

\section{(2) Blowing Test}

The blowing test aimed at ascertaining safety from an explosion and permitting a discussion on the subject of a converter internal pressure control system. With regard to the prevention of explosions, we conducted examinations and tests by taking into consideration all the possible cases as follows, and determined that the process was thoroughly safe.

(i) Entrance of the gate sealing water into the converter due to sudden change of oxygen pressure.

(ii) Abnormal reaction inside the converter.

(iii) Shocks at the time of additionally feeding fluxing material into the converter.

(iv) Electric power-off.

(v) Explosion of coke dust at the time of preheating the converter lining.

(vi) Closing of the flue.

(vii) Partial omission of purge.

(viii) Failure of gas curtain.

The discussions on the hood pressure, while referring to the results of the aforementioned fundamental research on gas curtain, focused on how to grasp the dynamic characteristic of this equipment by means of various kinds of meters. As a result, we confirmed that, even if the damper control system was adopted at the inlet of the induced draft fan, the meter made a quick response to any variation of hood pressure by selecting the dust collector of sufficient low pressure loss, and thus achieving the aim of control of hood pressure.

\section{(3) Tests on the Change-Over Valve and the Gas Holder}

The three-way change-over valve discharges into the air the gas containing a low amount of carbon monooxide generated at the early and last stage of blowing. This was essential for recovering the $\mathrm{CO}$ rich gas from the middle stage and storing it in the gas holder, for further utilization. However, it was made clear that there would be a necessity to check the change of gas pressure and flow at various points in the equipment at the shifting operation of the three way valve for ascertaining a practical utility of this equipment, and, at the same time, by preventing a sudden change in static pressure in the circuit after the induced draft fan.

\section{(4) Dust Collector}

Regarding the dust collector, various discussions were also made on the use of combined dry- and wettype dust collectors. As a result, it was found that some dust collections proved to be unsuitable for the automatic control system of the converter due to great loss of internal pressure. Some were not desirable on account of the dust deposits on the inner wall of the collector and because of the low dust-collecting efficiency. Consequently, we gave up using the drytype dust collector, and decided to adopt the spray dust collector and the venturi scrubber. Thus, we obtained an increased dust collecting efficiency by using this equipment.

(5) Survey of the Characteristics of Dust Collected

During the blowing test, we surveyed the variation of the amount of dust caused by lapse of blowing time, and also made examinations of the particle size, distribution, composition and magnetism of dust collected by the dust collector.

\section{(6) Gas Analysis}

Continual inspection of the gas composition with the lapse of blowing time gives the most effective measure for the assumption of oxygen blowing conditions as well as an indication for varied operations such as selection of gas recovery time and purge. Particularly in the OG process, it was considered difficult to discern the blowing conditions by the flame, since the top of the converter was sealed tight- 
ly; and therefore continuous gas analysis was particularly important.

There was no special problem with the continuous carbon monooxide and carbon dioxide analyzers. However, we tried to place exceptional emphasis on the development of continuous oxygen and quick analyzers for the prevention of explosions. In the development, Fuji Electric Mfg. Co., Ltd. made energetic research, successfully developing a continuous oxygen analyzer, designed so as to make quick response to slight change in the amount of oxygen being blown in.

For the future utilization of recovered gas as raw materials in the organic chemical industry, we also made an analysis of the amounts of nitride, sulfide and phosphide contained in the recovered gas.

\section{Results at Test Plant}

As a result of the study on the equipment and development of operating technique, the OG process at the test plant proved superior and safe fully showing the possibility of the adoption of the OG process to a converter in practical use.

The pilot plant tests took about one year and four months, during which we performed more than 200 blowing tests.

\section{Practical Use of OG Process}

As a result of various basic tests described in chapter II, we were able to determine by October, 1960 that the OG process would be successful both in principle and in practical use.

At that time, the Tobata No. 2 LD converter plant construction program was in its final stage, and we were pressed to decide which we would adopt for disposing of waste gas, the waste heat boiler as before or the OG process. However, after discussions made on the basis of tests at the pilot plant, the merits of the plant in the case of application at the Tobata No. 2 LD converter, general problems, the world trend, and so on, the adoption of the OG process at the Tobata No. 2 LD converter plant was decided upon in November, 1960.

For about one year after the decision to employ the OG equipment, we made discussions principally on the following matters.

(1) Detailed specifications of the 130-ton converter OG equipment.

(2) Tests by the pilot plant to acquire technical know-how necessary for the operation of the 130-ton converter.

Particularly these problems about the shifting operation of the three-way valve, the recovery of gas, the effect of the curtain formed around the top of the converter, and the suitability of the dust collector.

(3) The control system of the OG equipment (hood pressure control, diluting amount and time, and order of sequence control).

(4) Explosion proofing mechanism.

(5) Elimination of danger, countermeasures against poisoning emergency, electric power off.

Thus, the construction of the plant was started in November, 1960, its test operation being made in accordance with the following since January, 1962.

i. 1st test run (individual test run): from January 4, 1962 to February 6, 1962

ii. 2nd test run (combination test run or cold test run): from February 4, 1962 to March 6, 1962

iii. 3rd test run (hot run test): from March 9, 1962 to the end of April, 1962

A part of the 3rd test run and various kinds of tests made on the OG equipment were conducted in parallel with production; and in June, we performed the gas recovery operation, completing the test run.

The fact that no accident or trouble occurred through these test runs until the equipment successfully started practical operation is considered to be fully indicative of the safety of this process.

Table 2 gives a calendar of progress since the start of the OG Committee until the success of the test run with the OG equipment at the Tobata No. 2 LD converter plant.

Fig. 3 shows a sectional view of the Tobata No. 2 LD converter plant, while Fig. 4 gives a general layout of the OG process. The $1,250^{\circ} \mathrm{C}$ gas generated passes, in the unburned state, the hood part (3) gas cooler (8) and the 1st (9) and the 2nd dust collector (11) in which it is effectively cooled and dust in it is collected during passage. The gas temperature at the outlet of the induced draft fan (14) measures as low as $30^{\circ}-50^{\circ} \mathrm{C}$. As the $\mathrm{CO}$ content of gas is low at the early and the last stage of blowing, it is discharged into the atmosphere through the stack (17). However, the $\mathrm{CO}$ rich gas at the middle stage is recovered and stored in a gas holder (18) by shifting three way valve (15).

Since the commencement of operations with the OG process on March 9th, 1962, the Tobata No. 2 LD plant has been operating smoothly and continuously as expected, in respect to both working efficiency and safety, and now constantly maintains an output of 119,000 to 125,000 tons per month. The total tapping amount for about eighteen months from the start of operation till the end of August, 1963, has reached 12,141 heats and the steel ingots obtained reached 1,730,000 tons. Of the steel ingots produced, rimmed steel $(0.06-0.25 \% \mathrm{C})$ for strip accounts for about 95 per cent, and the rest is semi-killed steel. Table 3 gives the operational results of monthly steelmaking since the start of operation. As seen in the 
table, steelmaking by the LD converter equipped with OG process shows a high yield. This is a great economical advantage of the process.

Also noteworthy is that we conducted gas recovery tests during a 19-day period from June 22 to July 10 , 1962, gaining a satisfactory result; and accordingly we later performed gas recovery as a regular operation. The whole amount of the recovered gas is utilized as fuel for the boiler. Table 4 presents the trend of the results of gas recovering operations performed from June 1962, to August 1963.

The actual results of application of recovered gas

Table 2. Researching and construction of OG equipment in Tobata No. 2 LD converter plant



Fig. 3. Sectional view of Tobata No. 2 LD converter plant 


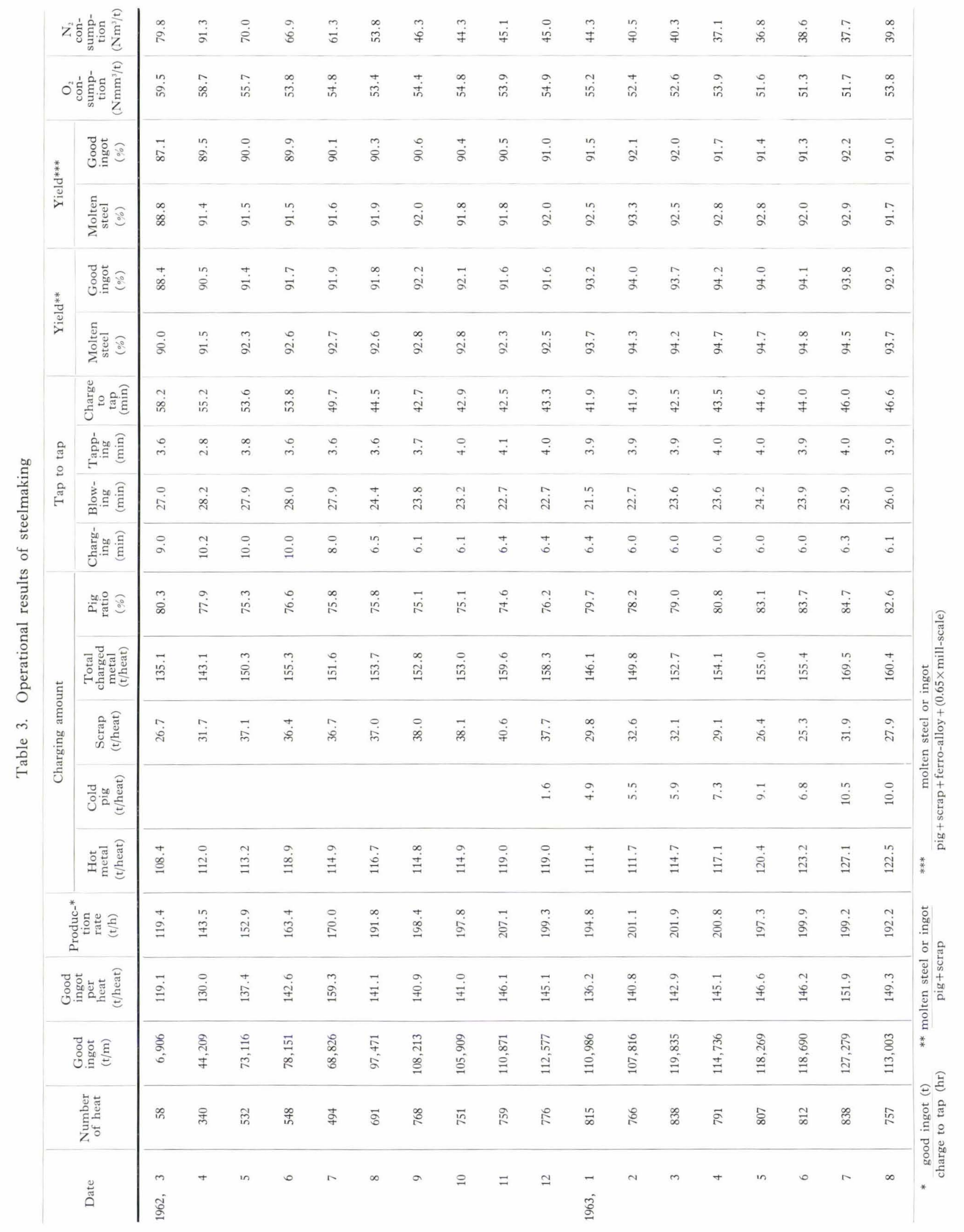


to a general boiler are shown in Table 5. This general boiler is now in use to supply 30 to 40 per cent of all the general steam to be used in Tobata Works.

Table 6 and Fig. 5 show the gas composition from the start to the end of blowing. In this case, only the $\mathrm{CO}$ rich gas is sent to the gas recovering equipment. At the early and last stage of blowing, the gas is diluted with nitrogen gas in order to prevent any big change in the flow of waste gas and also to assure safe operation by holding the composition of waste gas outside the explosion range.

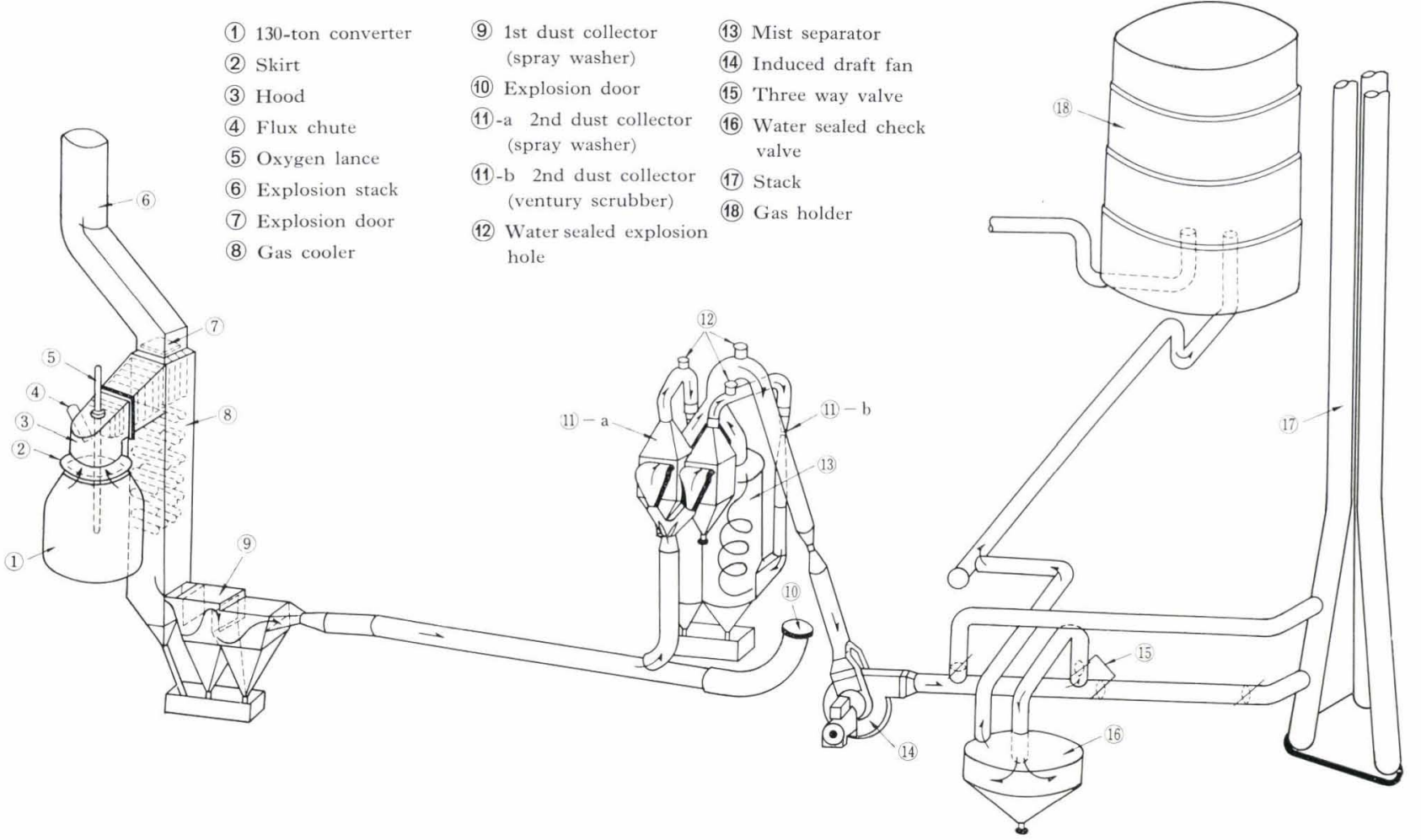

Fig. 4. General layout of OG process at Tobata No. 2 LD converter plant

Table 4. Monthly performance of gas recovery

\begin{tabular}{|c|c|c|c|c|c|c|c|c|c|c|}
\hline Date & $\begin{array}{l}\text { (A) } \\
\text { Number } \\
\text { of heats }\end{array}$ & $\begin{array}{l}\text { (B) } \\
\text { Number } \\
\text { of gas } \\
\text { recovered } \\
\text { heats }\end{array}$ & $\begin{array}{l}(\mathrm{C}) \\
\text { Total gas } \\
\text { recovered } \\
\left(\mathrm{m}^{3}\right)\end{array}$ & $\begin{array}{l}(\mathrm{B} / \mathrm{A} \times 100) \\
\text { Recovery } \\
\text { rate } \\
(\%)\end{array}$ & $\begin{array}{c}(\mathrm{C} / \mathrm{B}) \\
\text { Recovered } \\
\text { gas amount } \\
\text { per heat } \\
\left(\mathrm{m}^{3} / \text { heat }\right)\end{array}$ & $\begin{array}{c}\text { Recovered } \\
\text { gas amount } \\
\text { per ingot* } \\
\left(\mathrm{m}^{3} / \mathrm{t} \text {-ingot }\right)\end{array}$ & $\begin{array}{l}\text { Average } \\
\text { CO of } \\
\text { recovered } \\
\text { gas } \\
(\%)\end{array}$ & $\begin{array}{c}\text { Average } \\
\text { blowing } \\
\text { time } \\
(\mathrm{min} / \text { heat })\end{array}$ & $\begin{array}{l}\text { Average } \\
\text { recovering } \\
\text { time } \\
\text { (min/heat) }\end{array}$ & Remarks \\
\hline $\begin{array}{ll}1962 & 6 \\
7\end{array}$ & $\begin{array}{l}548 \\
494\end{array}$ & $\begin{array}{l}6 \\
5\end{array}$ & $\begin{array}{l}42,000 \\
30,400\end{array}$ & $\begin{array}{l}1.1 \\
1.0\end{array}$ & $\begin{array}{l}7,000 \\
6,180\end{array}$ & $\begin{array}{l}47.6 \\
56.2\end{array}$ & $\begin{array}{l}68.9 \\
66.1\end{array}$ & $\begin{array}{l}28.0 \\
27.9\end{array}$ & $\begin{array}{l}12.7 \\
12.2\end{array}$ & \multirow{14}{*}{$\begin{array}{l}\text { Gas recovery test } \\
\text { Gas recovery test } \\
\left\{\begin{array}{c}\text { Boiler combustion test } \\
\text { (Aug. 11-13, 25-28) }\end{array}\right.\end{array}$} \\
\hline 8 & 691 & 155 & 828,000 & 22.4 & 5,347 & 37.1 & 74.4 & 24.4 & 9.4 & \\
\hline 9 & 768 & 332 & $1,825,000$ & 43.2 & 5,497 & 39.8 & 79.4 & 23.8 & 11.2 & \\
\hline 10 & 751 & 621 & $3,688,300$ & 2.7 & 5,939 & 45.2 & 72.4 & 23.2 & 12.1 & \\
\hline 11 & 759 & 700 & $5,917,750$ & 92.3 & 8,458 & 57.4 & 73.4 & 22.7 & 12.7 & \\
\hline 12 & 776 & 644 & $5,099,600$ & 83.8 & 7,858 & 53.9 & 72.5 & 22.7 & 13.0 & \\
\hline 19631 & 815 & 674 & $4,512,200$ & 82.8 & 6,695 & 49.2 & 72.4 & 21.5 & 12.8 & \\
\hline 2 & 766 & 698 & $5,094,200$ & 91.1 & 7,298 & 50.9 & 71.7 & 22.7 & 14.4 & \\
\hline 3 & 838 & 780 & $6,611,760$ & 93.6 & 7,843 & 54.9 & 70.4 & 23.6 & 14.6 & \\
\hline 4 & 791 & 771 & $5,879,300$ & 97.5 & 7,626 & 52.5 & 70.8 & 23.6 & 13.4 & \\
\hline 5 & 807 & 723 & $5,933,200$ & 89.6 & 8,210 & 55.8 & 72.8 & 24.2 & 15.0 & \\
\hline 6 & 812 & 723 & $5,214,100$ & 96.2 & 6,680 & 45.5 & 74.2 & 23.9 & 11.9 & \\
\hline 7 & 838 & 717 & $4,461,600$ & 85.6 & 6,220 & 45.6 & 73.5 & 25.9 & 11.9 & \\
\hline 8 & 757 & 711 & $4,514,900$ & 94.0 & 6,350 & 47.9 & 71.5 & 26.0 & 11.6 & \\
\hline
\end{tabular}

Tables 7 and 8 give the dust collecting efficiency and the chemical composition of recovered gas at the Wakayama Works of Sumitomo Metal Industries, Ltd. which was the second company in Japan after Yawata to install and use OG equipment. The outstanding feature in the OG equipment is the dust as compared with dust in the case of waste heat boilers. The gas contains much $\mathrm{FeO}$ and metallic $\mathrm{Fe}$ which are less liable to oxidation because of the atmosphere in the flue. The dust particles are considerably large in diameter and greater in specific gravity, compared with

(13) Mist separato

14) Induced draft fan

Three way valve

b 2nd dust collector (17) Stack

(18) Gas holde 
Table 5. Results of OG gas utilization for boilers



OG gas using rate $(\%)$ was calculated on the basis of calorific value.

Table 6. Change of converter gas composition (N-2789 Tobata)

\begin{tabular}{c|l|l|l|l|r|r}
$\begin{array}{c}\text { Elasping } \\
\text { of blowing } \\
\text { time } \\
(\mathrm{min})\end{array}$ & $\begin{array}{c}\mathrm{CO}_{2} \\
(\%)\end{array}$ & $\begin{array}{c}\mathrm{O}_{2} \\
(\%)\end{array}$ & $\begin{array}{c}\mathrm{CO} \\
(\%)\end{array}$ & $\begin{array}{c}\mathrm{H}_{2} \\
(\%)\end{array}$ & $\begin{array}{r}\mathrm{N}_{2} \\
(\%)\end{array}$ & $\begin{array}{c}\text { Calorific } \\
\text { value } \\
\left(\mathrm{kcal} / \mathrm{Nm}^{3}\right)\end{array}$ \\
\hline 2 & 18.4 & 0 & 26.6 & 1.0 & 54.0 & 830 \\
4 & 19.6 & 0.3 & 43.4 & 1.8 & 34.4 & 1,380 \\
6 & 23.3 & 0.1 & 69.6 & 1.1 & 5.9 & 2,140 \\
8 & 21.3 & 0.2 & 73.3 & 1.0 & 4.2 & 2,250 \\
10 & 17.2 & 0.4 & 78.0 & 1.1 & 3.3 & 2,400 \\
12 & 13.4 & 0.3 & 81.5 & 1.1 & 3.7 & 2,500 \\
14 & 18.3 & 0.3 & 72.9 & 1.3 & 1.2 & 2,250 \\
16 & 12.4 & 0.2 & 81.4 & 0.9 & 5.1 & 2,490 \\
18 & 11.3 & 0 & 82.7 & 0.9 & 5.1 & 2,530 \\
20 & 9.4 & 0 & 85.7 & 0.9 & 4.7 & 2,600 \\
22 & 7.6 & 0.2 & 62.8 & 0.9 & 28.5 & 1,930 \\
24 & 8.8 & 0 & 14.9 & 0.9 & 75.4 & 480 \\
& & & & & &
\end{tabular}

Operational conditions (N-2789)

\begin{tabular}{l|c} 
Furnace life & $\begin{array}{c}135 \text { (6th campaign; } \\
\text { No. } 2 \text { converter) }\end{array}$ \\
\hline Skirt distance & $0 \sim 30 \mathrm{~mm}$ \\
\hline Flow rate of curtain $\mathrm{N}_{2}$ & $7,000 \mathrm{Nm}^{3} \mathrm{~h}$ \\
\hline Flow rate of $\mathrm{O}_{2}$ & $17,000 \mathrm{Nm}^{3} / \mathrm{h}$ \\
\hline Amount of hot metal & $114.1 \mathrm{t}$ \\
\hline E. Pt (C) & $0.05 \%$ \\
\hline Blowing time & $23.4 \mathrm{~min}$ \\
\hline
\end{tabular}

those in the case of the waste heat boiler; and accordingly, sufficient dust collecting efficiency is obtainable.

\section{Prospect of OG Process}

\section{Economy of $O G$ Process}

As compared with the conventional waste heat boiler, use of the OG process is markedly economical.

The economical advantages of OG process are as follows :

(1) Advantages in Construction Cost

The total installation cost of $O G$ process, including

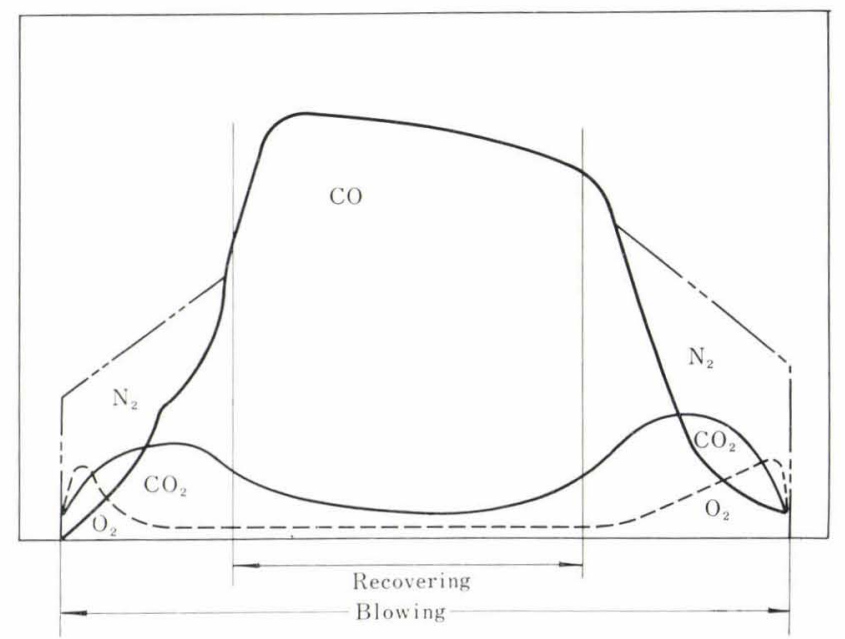

Fig. 5. Diagram of $\mathrm{N}_{2}$ dilution

gas holder and process boiler, is 50 to 60 per cent of that of the waste heat boiler including accumulator, dust collector, and boiler accessories in the converter plant of the same capacity. Further, if the economy in the construction cost of the plant building is considered, the economic difference between these two processes becomes even greater. Fig. 6 shows a comparison of gas cooler sizes of OG equipment and the waste heat boiler. As the vessel becomes larger, economical advantage becomes greater.

\section{(2) Higher Thermal Efficiency}

As seen in Fig. 7, the conventional waste heat boiler for the converter has a thermal efficiency of only $60 \%$ or less. On the other hand, total thermal efficiency of $70 \%$ is obtained when gas is recovered by the OG equipment, and is utilized as a heat source for the process boiler.

(3) Advantages in Steam Supply Adjustment

Because of intermittent blowing of the converter, steam supply from the waste heat boiler fluctuates from 
time to time, and accordingly even the boiler with $110 \mathrm{t} / \mathrm{hr}$ of peak load, generates on the average only $40 \mathrm{t} / \mathrm{hr}$ of steam. According to the fluctuation of steam supply, when the OG process is applied, an appropriate operation becomes possible with the installation of the process boiler as a source of steam supply.

\section{(4) Advantages of Dust Collecting Equipment}

As the unburnt gas is directly admitted to the dust collector in the OG process, the volume of the gas is kept one sixth smaller and the size of the dust collector can therefore be smaller.

Further, as the dust is prevented from changing into $\mathrm{Fe}_{2} \mathrm{O}_{3}$ and kept in a larger particle state with a rich content of $\mathrm{FeO}$, metallic $\mathrm{Fe}$, and $\mathrm{Fe}_{3} \mathrm{O}_{4}$, the mechanism of the dust collector and sludge treating equipment can be simplified.

\section{(5) Advantages in Utilizing Recovered Gas}

Calorific value of the recovered gas is approximately $2,300 \mathrm{kcal} / \mathrm{Nm}^{3}$. Therefore, recovered gas can well be used as fuel. Besides, it can conceivably be utilized as raw material in the field of organic chemical synthesis and in iron making.

\section{(6) Balance of $\mathrm{N}_{2}$}

The amount of $\mathrm{N}_{2}$ to be used for sealing the clearance between the converter mouth and the OG equipment and also for purging space incurvations, etc. is less than about $40 \mathrm{~m}^{3} / \mathrm{t}$ steel in the case of the Tobata No. 2 LD converter (130-t). This is fully satisfied by utilizing $\mathrm{N}_{2}$ generated as a by-product at the time of manufacturing pure oxygen.

\section{Diversion of Thomas Converter}

Along with the progress of the oxygen converter process, there is a tendency that the Thomas converter will be remodeled to an oxygen converter. In this case, however, there will inevitably occur the problem of waste gas and dust disposal; and consequently it may well be considered that the unburned dust collecting and gas recovering systems will be adopted much more widely than the waste heat boiler system.

Table 7. Dust collecting efficiency (Wakayama Works of Sumitomo Metal Industries, Ltd.)

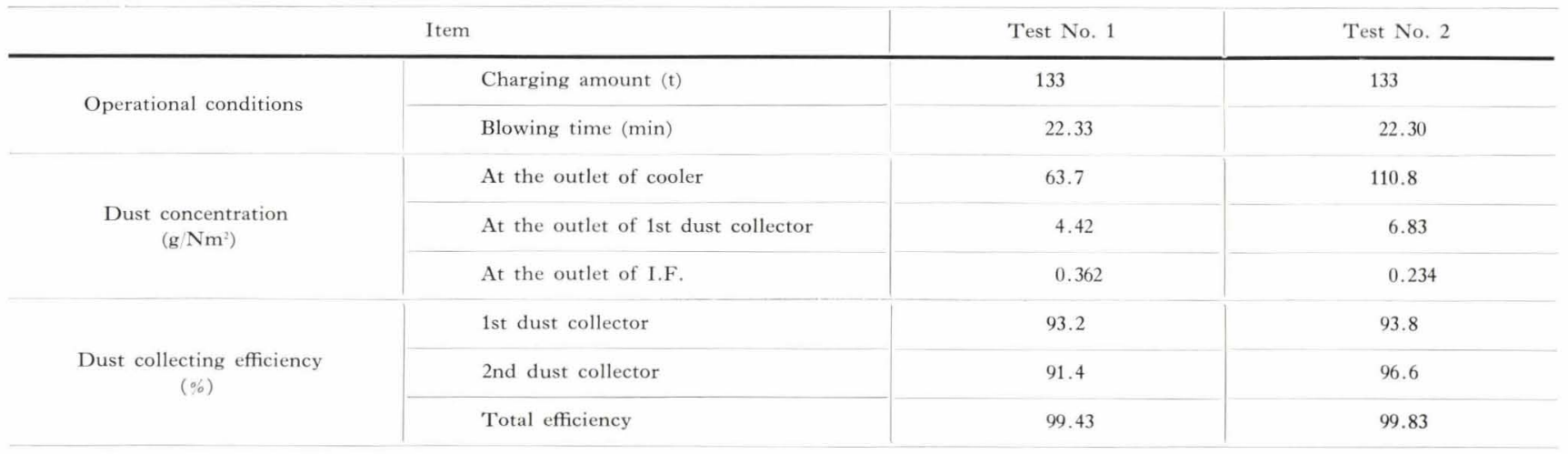

Table 8. Dust composition (Wakayama Works of Sumitomo Metal Industries, Ltd.)

(Unit : \%)

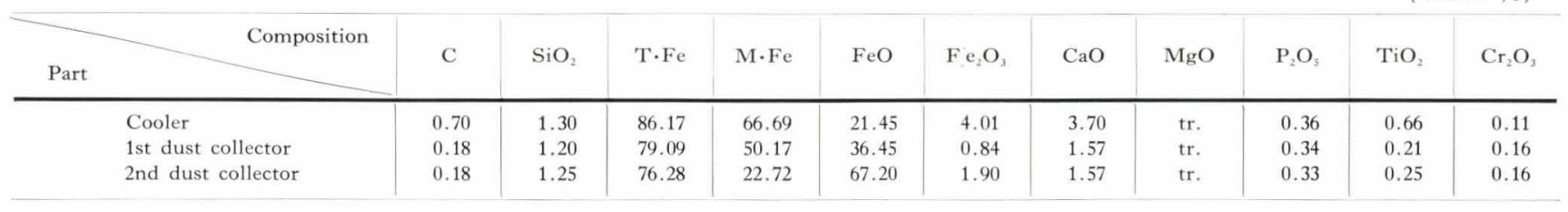

Table 9. A list of the unburnt converter gas processes

\begin{tabular}{|c|c|c|c|c|c|c|}
\hline Process & Company & Works & $\begin{array}{l}\text { Converter } \\
\text { capacity }\end{array}$ & $\begin{array}{c}\text { Gas } \\
\text { utilization }\end{array}$ & $\begin{array}{l}\text { Steel ingot } \\
\text { obtained } \\
(t)\end{array}$ & $\begin{array}{l}\text { Operation } \\
\text { starting } \\
\text { period }\end{array}$ \\
\hline OG & $\begin{array}{c}\text { Yawata Iron \& Steel } \\
\text { Co., Ltd. }\end{array}$ & Tobata Works & $130-t \times 2$ & Fuel & 1730,000 & Mar. 1962 \\
\hline OG & $\begin{array}{l}\text { Sumitomo Metal } \\
\text { Industries, Ltd. }\end{array}$ & Wakayama Works & $110-\mathrm{t} \times 2$ & Fuel & 450,000 & Feb. 1963 \\
\hline IRSID-CAFL & USINOR & Dunkerque & $130-t \times 2$ & None & ? & Dec. 1962 \\
\hline Krupp & DHHU & Hörde & $130-t \times 2$ & None & ? & May 1963 \\
\hline
\end{tabular}




\section{Application of $O G$ Process to $L D-A C$ Process}

The LD-AC process presently being developed in Europe is a process of blowing both pure oxygen and lime fowder together into the steel bath. Meanwhile,



OG process

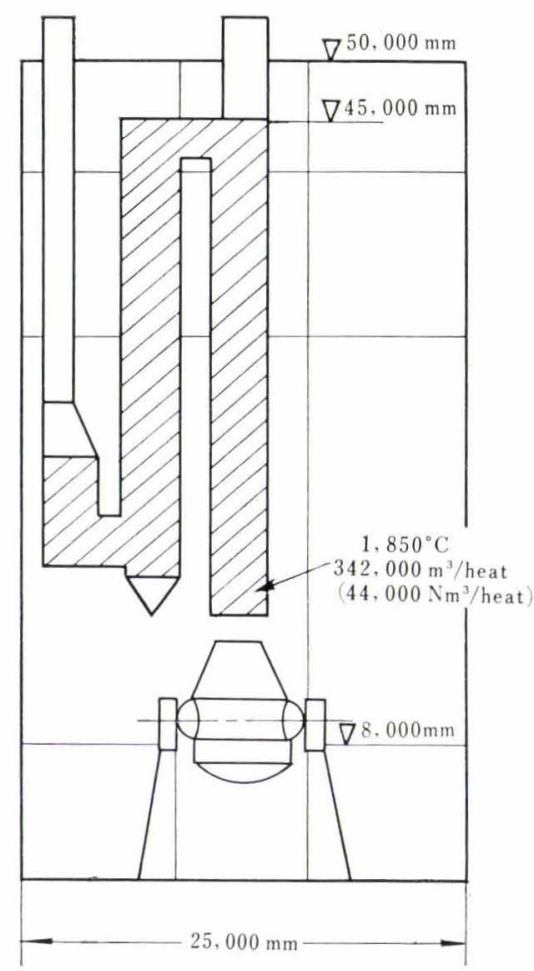

Waste heat boiler

Fig. 6. Comparison of sizes of gas coolers for 130-t converter a study for the application of the OG process to the LDAC process has already been started.

\section{Results of Unburnt Converter Gas Process}

Being very economical as described above, unburnt converter gas process is currently attracting keen attention of the steel industry in every country. And a few iron and steel plants have already adopted the system. However, none of these process are designed to recover gas, but are of the unburnt discharging type.



OG process

Total heat: $245,500 \mathrm{kcal} / \mathrm{t}$ steel Recovery: $\quad 172,000(70 \%)$ Loss : $\quad 73,500(30 \%)$

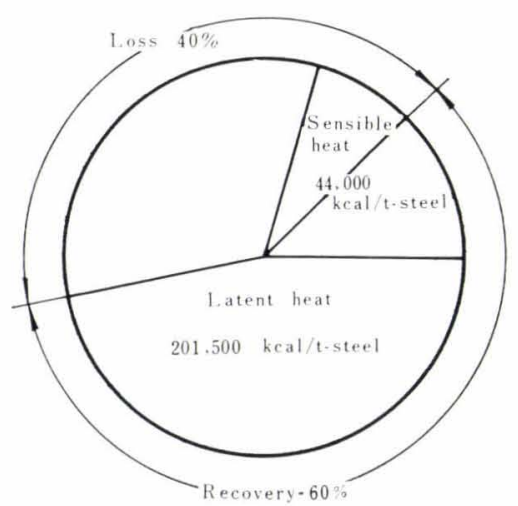

Waste heat boiler

Waste gas temperature at outlet of boiler : $\quad 350^{\circ} \mathrm{C}$

Total heat:

$245,500 \mathrm{kcal} / \mathrm{t}$ steel Recovery : $147,000(60 \%)$ Loss : $98,500(40 \%)$

Sensible heat is recovered as hot water at gas cooler. Latent heat is recovered in the gas state and the gas is used for process boiler fuel.

Fig. 7. Comparison of thermal efficiency between waste heat boiler and $O G$ process 
Therefore, although the gas cooling and dust collecting equipment may be designed compactly, there is no merit of practical utilization of recovered gas. A listing of the unburnt converter gas process, including the OG process, is shown in Table 9.

\section{Export of Technical Know-How}

In Japan, the OG process has already been adopted, by Yawata Iron \& Steel Co., Ltd., and the Wakayama Works of Sumitomo Metal Industries, Ltd. In both plants, the process has been performed smoothly attracting the attention of iron and steel machinery manufacturers in many countries abroad. We are now receiving many applications from them for technological tie-ups. Of these foreign manufacturers, DEMAG and BAUMCO of West Germany, VÖEST of Austria, and Loftus Engineering Co. of the U.S.A. concluded agreements for a technical tie-up with the joint group of Yawata Iron \& Steel Co., Ltd. and Yokoyama Engineering Co., Ltd. Some others are now negotiating with us for the conclusion of agreements for technical tie-ups. We further expect that some iron and steel plants in Europe and the U.S.A. will adopt the OG process in the near future.

\section{General Review of the Development of $O G$ Process}

We have described the progress of development and industrialization of the OG process. Just as, " Rome was not built in a day ", many years and months passed and many people's efforts were expended before the process was successfully industrialized.

To review the major factors of the success of this development, we have to mention that the joint research by many people with the OG Committee as the leader, was performed very smoothly, and achieved great success. Yawata Iron \& Steel Co., Ltd. undertook the performance of various tests for the actual adoption of the concept; Yokoyama Engineering Co., Ltd. added discussions and examinations with respect to the equipment as boiler makers; and Fuji Electric Mfg. Co., Ltd., contributed greatly to development of the process by producing high-precision meters. Also to be noted is that, as regards the theoretical foundation on the prevention of explosion, we asked K. Yamazaki, professor of Tokyo University, and R. Goto, professor of Kyoto University to render us their theoretical aid. Research and development in these various fields all together contributed to the bearing of superb fruit. 